\title{
Knowledge, attitude and practice of health care practitioners in Saudi Arabia, with regard to prevention of vitamin $D$ deficiency in infancy
}

\author{
Laila A. AlBishi, MD, Kousalya Prabahar, PhD, Yara M. Albalawi, Medical Student, Shahad A. Albalawi, Medical Student, \\ Ashwaq A. Abosalem, Medical Student, Wjdan A. Alqarni, Medical Student, Salha A. Almarhapi, Medical Student, \\ Maram M. Albalawi, MBBS.
}

\begin{abstract}
الأهداف : قياس معرفة وأساليب وممارسات الممارسين الصحيين

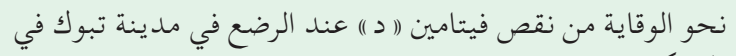

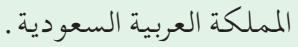

الطريقة : تم إستخدام إِستبيانات لقياس المعرفة وأساليب وممارسة

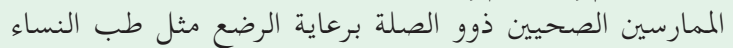

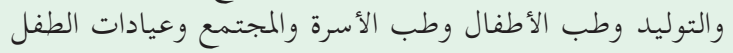

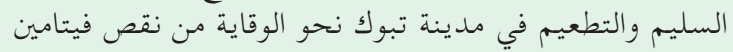

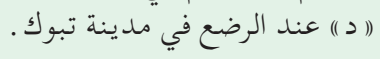

النتائج : على الرغم من أن الدراسة أظهرت فهم جيد لأهمية إنها

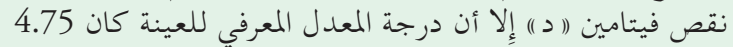

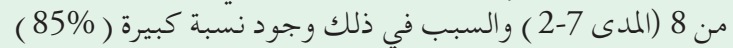

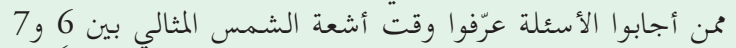

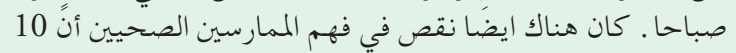

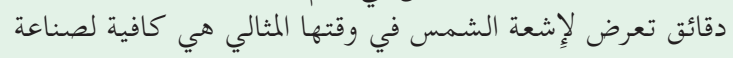

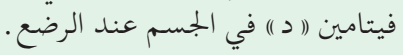

الحخاتمة: هذه الدراسة تشير إلىى حاجة المملكة العربية السعودية

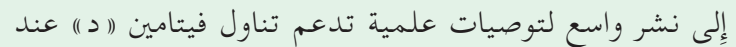

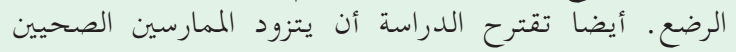

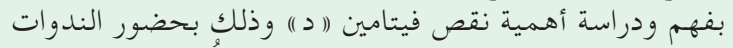

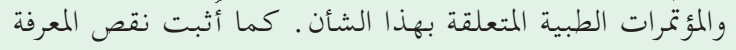

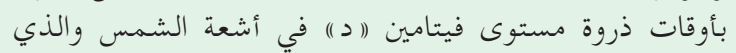

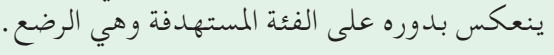

Objectives: To understand the knowledge, attitude, and practice of healthcare practitioners in Saudi Arabia, with regard to vitamin $\mathrm{D}$ supplementation.

Methods: A cross-sectional survey was conducted among healthcare practitioners in the Tabuk region of Saudi Arabia between January 2015 and December 2016. A questionnaire assessing knowledge, attitude and practice with regard to prevention of vitamin $\mathrm{D}$ deficiency was distributed to 100 healthcare practitioners.

Results: There was a good understanding of the importance of vitamin D deficiency; and overall practices were good. The average knowledge score was $4.75 / 8$ (range $2-7$ ), largely due to $85 \%$ of recipients identifying sun exposure between 6-7 am as the optimal time. There was a lack of understanding also, that as little as 10 minutes exposure is of benefit.

Conclusion: This study highlights the need for distribution of the recommendations for vitamin D supplementation in KSA, as widely as possible. This study suggests that healthcare practitioners understand the importance of correction of vitamin $\mathrm{D}$ deficiency. Deficiencies in knowledge with regard to sun exposure were identified. Dissemination of this information is, therefore, likely to impact significantly on the practice of a receptive clinical population.

Saudi Med J 2018; Vol. 39 (6): 603-608 doi: 10.15537/smj.2018.6.22238

From the Pediatric Department (AlBishi), Faculty of Medicine (Albalawi MY, Albalawi AS, Abosalem, Alqarni, Almarhapi, Albalawi MM), from the Faculty of Pharmacy (Prabahar), University of Tabuk, Tabuk, Kingdom of Saudi Arabia.

Received19th February 2018. Accepted 26th April 2018.

Address correspondence and reprint request to: Dr. Laila A. AlBishi, Assistant Professor, Pediatric Department, Faculty of Medicine, University of Tabuk, Tabuk, Kingdom of Saudi Arabia. E-mail: lalbishi@ut.edu.sa

ORCID ID: orcid.org/0000-0002-4677-3581

Disclosure. Authors have no conflict of interests, and the work was not supported or funded by any drug company. 
$\mathrm{T}$ he Kingdom of Saudi Arabia (KSA) receives $>3600$ sunlight hours each year with a high UV index. Despite this, in common with other countries in the Middle East, vitamin D deficiency is common. ${ }^{1-6}$ In KSA, $40-80 \%$ of neonates have undetectable vitamin D levels at birth. ${ }^{6}$ This paradox may be explained by sociocultural factors, in particular prolonged breastfeeding without vitamin D supplementation and limited exposure to sunlight, in particular in women, due to the use of fully-covered clothing. ${ }^{7}$ Neonates born to mothers with hypovitaminosis $\mathrm{D}$ are at significantly higher risk of developing rickets. The American Academy of Pediatricians recommends a daily intake of $400 \mathrm{IU}$ of vitamin D. ${ }^{8}$ The first recommendations for vitamin D supplementation, specifically for $\mathrm{KSA}$, were published this year by King Saud University as a result of a collaborative effort between the European Society for Clinical and Economic Aspects of Osteoporosis (ESCEO) and local experts., ${ }^{910}$ This committee recommended supplementation with 1000-2000 IU of vitamin D daily, as a safe and feasible option, in both mothers and babies ${ }^{10}$ and acknowledged that $90-100 \%$ of pregnant women suffer vitamin D deficiency in KSA. ${ }^{11}$

In the absence of national guidelines, there has been significant variation in healthcare professionals' attitudes towards vitamin D supplementation in KSA. A recent study demonstrated healthcare practitioners from the Dammam region to have a favorable attitude towards vitamin D supplementation. ${ }^{12}$ However, this study suggested also that knowledge and practices of healthcare practitioners could be improved. Of the 93 healthcare practitioners they enrolled, knowledge of vitamin D was excellent in only $30 \%$ and only $60 \%$ prescribed supplementation regularly. This study did not explore the underlying factors that could lead to variation in the prescription rate of vitamin $\mathrm{D}$. If the incidence of vitamin D deficiency is to decrease in KSA, engagement of clinicians with the policies set out in the recent recommendations is essential.

We explored also knowledge with regard to sunlight exposure. Detailed knowledge is available with regard to vitamin D3 generation at different times of day, in different regions of Saudi Arabia, in Summer and Winter. ${ }^{13,14}$ The advice in the guidelines balances these data against the increased risk of skin cancer from UVB exposure, recommending sunlight exposure 3-4 times each week, in Summer between 9:00-10:30 and 14:00-15:00 and in Winter between 10:00-14:00. ${ }^{10}$ We conducted a survey among healthcare practitioners in the Tabuk region to understand the knowledge, attitude and practices with regard to vitamin D supplementation and the factors that contribute to any variation seen. Specifically, we addressed the hypothesis that better knowledge of vitamin D biology and the incidence and consequences of vitamin D deficiency would correlate with better attitudes and practices with regard to vitamin D supplementation.

Methods. A cross-sectional survey was conducted among healthcare practitioners in the Tabuk region of KSA between January 2015 and December 2016. Local ethical approval was given by the committee of the Faculty of Medicine, University of Tabuk (Serial number 39/052//19489). The latitude of Tabuk region is $28.3835^{\circ} \mathrm{N}, 36.5662^{\circ} \mathrm{E}$. This area has a population of approximately 800,000 . The healthcare practitioners who were willing to participate and complete the questionnaire were included for the study and those who are not willing to participate in the study were excluded. One hundred healthcare practitioners were invited to complete the survey, all of who replied. The study population invited represents $7 \%$ of the total available population, based on the pilot study. These practitioners were from both government and private hospitals, and represented a range of practitioners involved in child care as set out in Table 1. Face-to-face interviews were conducted, at which consent was taken, the background to the questionnaire was outlined and the questions explained. A 10-min self-administered 2-part questionnaire developed by the researchers after discussions with experts and a literature review was used to achieve the objective of the study. The first part covered demographic data that included: age, gender and number of years of practice. The second part had 8 questions each of knowledge, attitudes and practices related to Vitamin D supplementation.

We hypothesized that healthcare practitioners' knowledge with regard to vitamin $\mathrm{D}$ would determine their attitudes and practices with regard to prescribing of vitamin $\mathrm{D}$ for supplementation in infants. To test this hypothesis, we calculated a total knowledge score for each respondent (maximum score 8) and determined if knowledge score correlated with any of the other variables assessed. There were 8 questions to assess knowledge and each correct answer carries a score of 1 . The practitioners will get a score of 8 , if they answered all the questions correctly and a score of 0 , if they did not answer any of the questions correctly.

Continuous variables are presented as mean \pm standard deviation. Categorical variables are presented as exact values (total number of respondents 100). Student's $t$ test was conducted to test the difference between continuous variables. Pearson's correlation test was 
conducted to find the association of knowledge score with continuous demographic variables (age and years of experience). Analysis of variance (ANOVA) was conducted to check the association of categorical variables (gender, job type, and work location) with the knowledge score. Tukey's post-hoc test was used to identify subgroup associations. Influence of knowledge score on attitudes was tested also using ANOVA. The influence of knowledge score on practice was tested using Point Biserial Correlation test. A 2 tailed $p$-value of $<0.05$ was considered statistically significant.

Descriptive analyses were conducted with Microsoft Excel and statistical analyses were conducted with Statistical Package for Social Sciences version 20.0 (SPSS Inc, IL, USA, 2016).

Results. We contacted 100 healthcare workers, all of who responded. The participants' mean age was $36.2 \pm 10.9$ years (range 23-63). Fifty-five percent were women (Table 1).

The average knowledge score of participants was $4.75 \pm 1.1$ (range 2-7) with none of the participants scoring 8 (Table 2). With regard to the best time for sun exposure, respondents were given 3 choices: early in the day (6-7 am), middle of the day $(9 \mathrm{am}-4 \mathrm{pm})$ and late in the day (after $4 \mathrm{pm})$. The knowledge scores were significantly affected by $85 \%$ of respondents believing that the best time of day to get vitamin $\mathrm{D}$ from sun

Table 1 - Demographic characteristics of 100 healthcare workers.

\begin{tabular}{|c|c|}
\hline Characteristics & $\mathrm{N}, \mathrm{Mean} \pm \mathrm{SD}$ \\
\hline Age (years) & $36.21 \pm 10.89$ \\
\hline Range & 23-63 \\
\hline Male \% & 45 \\
\hline Years of practice & $12.06 \pm 10.63$ \\
\hline \multicolumn{2}{|l|}{ Range } \\
\hline \multicolumn{2}{|l|}{ Job titles* } \\
\hline Consultant Doctor & 12 \\
\hline Intern Doctor & 8 \\
\hline Resident Doctor & 44 \\
\hline Specialist Doctor & 27 \\
\hline Well baby clinic nurse & 9 \\
\hline \multicolumn{2}{|l|}{ Working place } \\
\hline Government hospital & 98 \\
\hline Private Hospital & 2 \\
\hline \multicolumn{2}{|c|}{$\begin{array}{l}\text { *Consultant - a consultant a "higher rank" than the specialist, } \\
\text { Intern - a physician in training who has completed medical school } \\
\text { and has a medical degree, but does not yet have a full license to practice } \\
\text { medicine unsupervised, Resident - who practices medicine, usually in a } \\
\text { hospital or clinic under the direct or indirect supervision of an attending } \\
\text { physician, Specialist - Practices one branch of medicine, Well baby clinic } \\
\text { nurse - work in health centres, weighing the babies and advice is given } \\
\text { on infant feeding, immunizations; they are not necessarily working in } \\
\text { child health or women's health }\end{array}$} \\
\hline
\end{tabular}

exposure was early in the day (6-7 am) and a lack of recognition that only 10 minutes exposure was needed to generate significant amounts of vitamin D (Table 3).

With regard to attitudes to vitamin D supplementation (Table 4), overall there seemed to be good awareness of its importance, with $72 \%$ of respondents understanding that vitamin $\mathrm{D}$ deficiency in infancy can be prevented in the antenatal period, $73 \%$ understanding that assessment of vitamin D levels in pregnant women is essential to prevent vitamin $\mathrm{D}$ deficiency in infants and $84 \%$ recognizing the association between breast feeding and vitamin $\mathrm{D}$ deficiency. Positive attitudes were evident with $80 \%$ of respondents believing greater awareness in society to be important and 88\% believing attendance at a workshop/ conference to be useful in tackling this problem.

Table 2 - Distribution of knowledge score by 100 healthcare workers.

\begin{tabular}{lc}
\hline Characteristics & Knowledge score (0 to 8) \\
\hline Gender & $4.84 \pm 1.19$ \\
Male & $4.67 \pm 1.00$ \\
Female & \\
Job titles & $5.33 \pm 0.89$ \\
Consultant doctor & $4.63 \pm 1.19$ \\
Intern doctor & $4.73 \pm 1.04$ \\
Resident doctor & $4.70 \pm 1.27$ \\
Specialist doctor & $4.33 \pm 0.71$ \\
Well baby clinic nurse & $4.72 \pm 1.07$ \\
Workplace & $6.00 \pm 1.41$ \\
Government hospital & \\
Private hospital & *Consultant - a consultant a "higher rank" than the specialist, \\
Intern - a physician in training who has completed medical school \\
and has a medical degree, but does not yet have a full license to practice \\
medicine unsupervised, Resident - who practices medicine, usually in a \\
hospital or clinic under the direct or indirect supervision of an attending \\
physician, Specialist - Practices one branch of medicine, Well baby clinic \\
nurse - work in health centres, weighing the babies and advice is given \\
on infant feeding, immunizations; they are not necessarily working in \\
\multicolumn{2}{c}{ child health or women's health } \\
\hline
\end{tabular}

Table 3 - Knowledge scores in generating significant amounts of vitamin D.

\begin{tabular}{lc}
\hline Question & $\begin{array}{c}\text { Percentage } \\
\text { score }\end{array}$ \\
\hline Best time to start giving Vitamin D supplements & 74 \\
Good dietary sources of Vitamin D & 82 \\
Storage of non-functional form of vitamin D & 50 \\
Value of 25 hydroxy vitamin D that is indicative of & 68 \\
vitamin D deficiency & 90 \\
Mineral Vitamin D help the body to absorb & 100 \\
$\begin{array}{l}\text { Vitamin D deficiency causes } \\
\text { What is the best time of day to get vitamin D from } \\
\text { the sun }\end{array}$ & 14 \\
$\begin{array}{l}\text { Duration of sun exposure per day for infants to get } \\
\text { vitamin D }\end{array}$ & 25 \\
\hline
\end{tabular}


Practices overall were good. A majority (77\%) of respondents reported prescribing vitamin $\mathrm{D}$ supplements for infants who are breast fed with $88 \%$ advising parents about the importance of vitamin $\mathrm{D}$ with $64 \%$ prescribing vitamin $\mathrm{D}$ for pregnant women and $80 \%$ following the recommendations of the American Pediatric Association. Sixty-seven percent prescribe vitamin D for all infants, with 400 IU being the most common dose prescribed. Only 12 respondents prescribed higher doses (600 IU $n=9,800$ IU $n=3$ ). (Table 5). Correlation test of the knowledge score and 8 practices questions showed a significant positive association of knowledge with the practice regular prescription of vitamin $\mathrm{D}$ in infants $(\mathrm{r}=0.277$; $p=0.006 ; \mathrm{n}=99$ ) (Table 6). No other practices were significantly associated with the knowledge score. (using Point Biserial correlation test). Similarly, none of the attitude questions were significantly associated with knowledge scores. The only practice to be significantly associated with knowledge score was the practice of regular prescription of vitamin D in infants $(p=0.006)$ (Table 5).

Table 4 - Attitudes towards prevention of vitamin D deficiency.

\begin{tabular}{|c|c|c|c|}
\hline Attitude Statement & Yes & No & $\begin{array}{l}\text { Don't } \\
\text { know }\end{array}$ \\
\hline Vitamin D deficiency in infancy could be preventable during the antenatal period & 72 & 19 & 9 \\
\hline There is a relationship between breast feeding and vitamin D deficiency & 84 & 11 & 5 \\
\hline There is an association between vitamin D deficiency and low birth weight & 54 & 31 & 15 \\
\hline Assessing vitamin $\mathrm{D}$ level in pregnant women is essential to prevent vitamin D deficiency in infants & 73 & 12 & 15 \\
\hline Screening for vitamin D deficiency should be done for infant who have affected sibling & 74 & 21 & 5 \\
\hline Healthcare practitoners are adequately aware of vitamin D deficiency in infants & 58 & 23 & 19 \\
\hline Familiarity with vitamin $\mathrm{D}$ in society would help in preventing vitamin $\mathrm{D}$ deficiency & 80 & 11 & 9 \\
\hline $\begin{array}{l}\text { Attending conference/workshop on vitamin D deficiency in children would enhance prevention of vitamin } \\
\mathrm{D} \text { deficiency in infants }\end{array}$ & 88 & 9 & 3 \\
\hline
\end{tabular}

Table 5 - Practices of health care practitioners with regard to prevention of vitamin d deficiency.

\begin{tabular}{lc}
\hline Practice & $\begin{array}{c}\text { Positive } \\
\text { response } \\
(\%)\end{array}$ \\
\hline Do you prescribe vitamin D supplement for infant who is exclusively breast fed? & 77 \\
Do you measure concentration of 25 OH vitamin D to assess vitamin D status? & 69 \\
Do you advise parents about the importance of vitamin D? & 88 \\
Do you prescribe vitamin D supplement for pregnant women? & 64 \\
Do you follow the recommendations of American pediatric association? & 80 \\
Do you regularly prescribe vitamin D for all infants? & 67 \\
What dose of vitamin D do you prescribe for infants? & 22 \\
200 IU & 66 \\
400 IU & 9 \\
600 IU & 3 \\
800 IU & 88 \\
Do you ask parents about sun exposure for them and their infants? & \\
\hline
\end{tabular}

Table 6 - A point biserial correlation test of knowledge score and practices

\begin{tabular}{|c|c|c|c|}
\hline Questions & $\mathrm{n}$ & $r$ & $P$-value \\
\hline Do you give vitamin D supplement for infant who is exclusively breast-fed? & 99 & 1.22 & 0.23 \\
\hline Do you measure the concentration of 25 -hydroxy vitamin D for assessment of vitamin D status? & 97 & -0.13 & 0.89 \\
\hline Do you give advice to parents during the clinic about the importance of vitamin D? & 99 & 0.01 & 0.92 \\
\hline Do you give vitamin d supplement for pregnant women? & 91 & 0.05 & 0.67 \\
\hline Do you follow the recommendations of American pediatric association for vitamin D supplementation in infancy? & 96 & 0.10 & 0.32 \\
\hline Do you regularly prescribe vitamin D supplements for all infants? & 99 & 0.28 & 0.006 \\
\hline What is the prescribed dose of vitamin $\mathrm{D}$ for infants? & 95 & 0.02 & 0.89 \\
\hline Do you ask parents about sun exposure for them and their infants? & 99 & -0.02 & 0.87 \\
\hline
\end{tabular}


Discussion. Most of the participants had low knowledge scores. But still more than half $(77 \%)$ of the healthcare practitioners surveyed, prescribed vitamin D supplementation for all infants. This percentage was higher compared with other studies. One-third of the physicians (27.1\%) in an American study ${ }^{15}$ and 29\% of family physicians in a study of Military Physicians ${ }^{16}$ recommended vitamin D supplementation for all infants. This suggests that physicians in Saudi Arabia are aware of the specific problem of vitamin D deficiency in Middle Eastern populations. Furthermore, although the knowledge score overall was not high, $74 \%$ of respondents recognized the importance of starting vitamin D supplementation in infancy and most (84\%) were aware of the association with breast feeding. It is perhaps therefore not surprising that physicians in Saudi Arabia were more likely to prescribe vitamin D supplementation for both breast- and bottle-fed infants than American counterparts.

An important point to note here is that there is no specific recommendation from the Saudi Ministry of Health on vitamin D supplementation for infants. Eventhough different pediatric associations laid regulations for vitamin D supplementation, none of these are specific to Saudi Arabia or Middle East. ${ }^{8,17}$ Most respondents in this survey $(80 \%)$ followed the American Pediatric Association guidelines, which recommend a lower dose than the King Saud University recommendations. Furthermore, the low knowledge scores were driven largely by poor understanding of the benefits and physiology of sun exposure. Specifically, in Saudi Arabia, it has been shown that the effectiveness of sun exposure in generating vitamin D differs through the day. The optimal time for peak vitamin $\mathrm{D}$ generation differs by region and by season. However, overall midday is optimal for vitamin $\mathrm{D}$ generation, although the high UVB exposure at this time may moderate recommendations with regard to the optimal time for sun exposure given the cancer risk. ${ }^{13}$ These findings underline the importance of detailed knowledge with regard to sun exposure and vitamin $\mathrm{D}$ for physicians in KSA. At the optimum time of day as little as 10 minutes exposure generates significant amounts of vitamin D. This survey highlighted a lack of understanding of the importance of time of day and how much exposure is needed. However, $88 \%$ of GPs still asked about sun exposure and advised about the importance of vitamin D. It is thus the detail, not the general understanding, of the importance of sun exposure that seems to be lacking.

Healthcare practitioners in Tabuk region are understanding of and engaged with the problem of vitamin D deficiency in infants in SaudiArabia. Guidance with regard to the details of correction of this problem may therefore be expected to have significant impact. We would urge dissemination of the recommendations made available recently, in order to ensure best practice for the Saudi population is instituted.

In conclusion, the healthcare practitioners showed positive attitude towards vitamin $\mathrm{D}$ supplementation which is a welcoming symptom for the new born's positive health. The Government should implement new guidelines so that the healthcare practitioners can improve their practice for the well-being of the infants.

All 100 healthcare practitioners invited to participate in the survey completed questionnaires, eliminating the risk of non-response bias.

Study limitations. The major limitation of this study is small sample size. Generalizability to populations other than KSA and the potential issues around generalizability are the other limitations.

The findings of this study can be useful in preparing new guidelines regarding vitamin D supplementation.

\section{References}

1. Naeem Z, AlMohaimeed A, Sharaf FK, Ismail H, Shaukat F, Inam SB. Vitamin D status among population of Qassim region, Saudi Arabia. Int J Health Sci (Qassim) 2011; 5: 116-124.

2. Al-Mogbel ES. Vitamin D status among adult Saudi females visiting primary health care clinics. Int J Health Sci (Qassim) 2012; 6: 116-126.

3. Mansour MMHK, Alhadidi KM. Vitamin D deficiency in children living in Jeddah, Saudi Arabia. Indian J Endocrinol Metab 2012; 16: 263-269.

4. Ardawi MS, Sibiany A, Bakhsh T, Qari M, Maimani A. High prevalence of vitamin D deficiency among healthy Saudi Arabian men: relationship to bone mineral density, parathyroid hormone, bone turnover markers, and lifestyle factors. Osteoporos Int 2012; 23: 675-686.

5. Al-Ghamdi MA, Lanham-New SA, Kahn JA. Differences in vitamin D status and calcium metabolism in Saudi Arabian boys and girls aged 6 to 18 years: effects of age, gender, extent of veiling and physical activity with concomitant implications for bone health. Public Health Nutr 2012; 15: 1845-1853.

6. El-Hajj Fuleihan G. Vitamin D deficiency in the Middle East and its health consequences for children and adults. Clinic Rev Bone Miner Metab 2009; 7: 77-93.

7. Baroncelli GI, Bereket A, El Kholy M, Audì L, Cesur Y, Ozkan $\mathrm{B}$, et al. Rickets in the Middle East: role of environment and genetic predisposition. J Clin Endocrinol Metab 2008; 93: 1743-1750.

8. Wagner CL, Greer FR. American Academy of Pediatrics Section on Breastfeeding, American Academy of Pediatrics Committee on Nutrition. Prevention of rickets and vitamin D deficiency in infants, children, and adolescents. Pediatrics 2008; 122: 1142-1152. 
9. Maalouf G, Gannagé-Yared M, Ezzedine J, Larijani B, Badawi S, Rached A, et al. Middle East and North Africa consensus on osteoporosis. J Musculoskelet Neuronal Interact 2007; 7: $131-143$.

10. Al-Daghri NM, Al-Saleh Y, Aljohani N, Sulimani R,Al-Othman AM, Alfawaz H, et al, Vitamin D status correction in Saudi Arabia: an experts' consensus under the auspices of the European Society for Clinical and Economic Aspects of Osteoporosis, Osteoarthritis, and Musculoskeletal Diseases (ESCEO). Arch Osteoporos 2017; 12: 1 .

11. Al-Shaikh GK, Ibrahim GH, Fayed AA, Al-Mandeel H. Impact of vitamin $\mathrm{D}$ deficiency on maternal and birth outcomes in the Saudi population: a cross-sectional study. BMC Pregnancy Childbirth 2016; 16: 119.

12. Babli AI, AlDawood KM, Khamis AH. Knowledge, attitude, and practice of general practitioners in Dammam, Saudi Arabia towards Vitamin D supplementation to infants. J Family Community Med 2015; 22: 135-139.
13. Alshahrani FM, Almalki MH, Aljohani N, Alzahrani A, Alsaleh Y, Holick MF. Vitamin D Light side and best time of sunshine in Riyadh, Saudi Arabia. Dermatoendocrinol 2013; 5 : 177-180.

14. Alamri F, Alshahrani F, Al-Saleh Y, Saeedi MY, Almalki MH, Al-Daghri N, et al Optimum Sun Exposure Times for Vitamin D Status Correction in Saudi Arabia. European Journal of Preventive Medicine 2015; 3: 147-154.

15. Shaikh U, Alpert PT. Practices of vitamin D recommendation in Las Vegas, Nevada. J Hum Lact 2004; 20: 56-61.

16. Sherman EM, Svec RV. Barriers to vitamin D supplementation among military physicians. Mil Med 2009; 174: 302-307.

17. Dratva J, Merten S, Ackermann-Liebrich U. Vitamin D supplementation in Swiss infants. Swiss Med Wkly 2006; 136: 473-481. 